\title{
P84 Co-polyimide/Nanocrystalline Cellulose (NCC)-based Tubular Carbon Membrane: Effect of Drying Times for Carbon Dioxide Separation at Elevated Carbonization Temperature
}

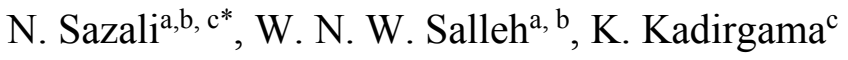 \\ aAdvanced Membrane Technology Research Centre (AMTEC), Universiti Teknologi \\ Malaysia, 81310 UTM Johor Bahru, Johor, Malaysia \\ ${ }^{b}$ Faculty of Chemical and Energy Engineering (FCEE), Universiti Teknologi \\ Malaysia, 81310 UTM Johor Bahru, Johor, Malaysia \\ ${ }^{\mathrm{c}}$ Faculty of Mechanical Engineering, Universiti Malaysia Pahang, \\ 26600 Pekan Pahang Darul Makmur, Malaysia
}

Submitted: 1/5/2018. Revised edition: 18/5/2018. Accepted: 28/5/2018. Published online: 4/6/2018

\begin{abstract}
In this study, the effect of drying time on the performance of tubular carbon membrane was investigated. P84 co-polyimide blends with Nanocrystalline cellulose (NCC)-based carbon membrane supported on ceramic tube was fabricated through the dip-coating technique. This study aims to investigate the effect of various drying times (12 hours, 24 hours, 3 days and 7 days) on the carbon dioxide separation properties. The gas permeation test of the resultant tubular carbon membrane was determined by using pure gas of $\mathrm{CO}_{2}$ and $\mathrm{N}_{2}$. In order to enhance the membrane performance, final carbonization temperature was executed at $800^{\circ} \mathrm{C}$ in Argon environment with flow rate of $200 \mathrm{~mL} / \mathrm{min}$. From the results, it was found that the best drying times was within 24 hours and such membrane showed the highest $\mathrm{CO}_{2} / \mathrm{N}_{2}$ selectivity $(66.32 \pm 2.18)$.
\end{abstract}

Keywords: Drying times, Dip-coating, P84 co-polyimide, Nanocrystalline cellulose, Carbon dioxide separation.

\subsection{INTRODUCTION}

It is estimated that global temperature will rise by $2^{\circ} \mathrm{C}$ to $4.5^{\circ} \mathrm{C}$ by 2100 and carbon dioxide $\left(\mathrm{CO}_{2}\right)$ emission to the atmosphere has become one of the major contributors to the increment of global temperature. Furthermore, it was reported that more than 30 billion tonnes of $\mathrm{CO}_{2}$ were emitted annually from human activities [1]. Various techniques have been used to mitigate the $\mathrm{CO}_{2}$ emission problems such as by using chemical and physical adsorption, solid adsorption, cryogenic distillation and membrane separation [2]. However, in these recent years, the application of membrane especially carbon membrane for gas separation has received a great attention from many researchers. Carbon membrane has become one of the best options for the development of new membrane technologies due to its stability and molecular sieving capability.

The most remarkable advantages of carbon membrane have been reviewed in order to emphasize on their utilization as separation instrument which makes it more promising than its counterpart such as polymeric membrane [3-5]. The utilization of carbon membrane is seen to be one of the promising materials for $\mathrm{CO}_{2} / \mathrm{N}_{2}$ gas 
separation due to few leading factors such as high thermal resistance, chemically stable, nanoporous structure and high $\mathrm{CO}_{2} / \mathrm{N}_{2}$ selectivities [6-8].

Generally, supported carbon membranes are preferred because it possesses high mechanical strength and thin separation layer. In order to fabricate enhanced structures of supported carbon membrane with a uniform and defect-free thin separation layer, dip coating method is employed. Dip coating method was applied in this study as it can produce thin separation layer with better separation performance.

In this research, P84 co-polyimides have been established and known as thermo resistant polymers and were applied in various applications, especially in the field of electronics [911]. The utilization of Nanocrystalline cellulose as additives is similar as previous study [12]. Interestingly, abundant amount of biopolymer i.e cellulose can be extracted from plant fibres and recycle materials which can be converted into NCC by sulfuric acid hydrolysis. Generally, the NCC can be produced from various materials such as discarded cigarette filters [13], sugar palm fibres [14], raw cotton and cotton stalk [15]. NCC possessed many advantages including high surface area, high crystallinity, low density, biodegradable, biocompatible and high mechanical strength. In addition, the rod-like nanostructure of NCC is potentially to be used as filler for nanocomposites.

Therefore, the application of NCC blend with P84 co-polyimide as the coating material on the carbon membrane was used in this study to enhance the $\mathrm{CO}_{2} / \mathrm{N}_{2}$ gas separation. Previous studies have been conducted on the effects of carbonization conditions such as heating rates [16], thermal soak time [17] as well as the carbonization final and stabilized temperature [18]. However, the effect of drying times of the membrane is still at their infancy. Hence, in this study the drying times of the membrane were varied at 12 hours, 24 hours, 3 days and 1 week. The fabricated supported carbon membrane was then characterized by SEM analysis and the performance of the carbon membrane for $\mathrm{CO}_{2} / \mathrm{N}_{2}$ gas separation was observed.

\subsection{METHODS}

\subsection{Materials}

P84 co-polyimide procured from Sigma Aldrich was used as a main precursor while N-methyl-2-pyrrolidone (NMP) as a solvent was purchased from Merck (Germany). All chemicals were directly used without further purification. Nanocrystalline cellulose (NCC) was in-house synthesized, according to the experimental procedures as reported in previous studies by [12]. Porous tubular ceramic support $\left(\mathrm{TiO}_{2}\right)$ with $8 \mathrm{~cm}$ in length, $3 \mathrm{~mm}$ thickness and average pore size of $0.2 \mu \mathrm{m}$ (porosity of 40 $50 \%$ ) was purchased from Shanghai Gongtao Ceramics Co., Ltd.

\subsection{Carbon Membrane Preparation}

Polymer solution consisting of $15 \%$ of P-84 (relative to total wt.) and NMP was prepared and stirred under constant stirring condition at $80{ }^{\circ} \mathrm{C}$. $7 \mathrm{wt} \%$ of NCC were added gradually into the solution and were continuously stirred until homogenous solution was obtained. Finally, all the polymer solutions were placed inside sonication bath for several hours in order to remove existing bubbles during stirring process.

The tubular support was then dipcoated for 45 minutes with 2 times coating-carbonization cycles. One of the useful and simple coating technique 
to prepare a supported carbon membrane is a dip-coating technique as this technique can produce a very thin top layer. In order to produce tubular membranes, ceramic tubes were immersed in the dope solution for 45minutes. Afterward, the resultant membranes were immersed in methanol for 2 hours, followed by placing it inside the oven at $100{ }^{\circ} \mathrm{C}$ for 12 hours, 24 hours, 3 days, and 1-week drying times to remove the solvent. The thickness of the resultant membrane has been measured by Vernier carliper. Dip-coating process comprises of five different stages which are immersion, start-up, deposition, evaporation and drainage.

Carbonization process of the supported polymeric membrane was conducted to prepare a carbon membrane. The supported polymeric membrane was heated at $800^{\circ} \mathrm{C}$ under Argon gas flow $(200 \mathrm{ml} / \mathrm{min})$ in Carbolite horizontal tubular furnace. The experimental procedures were conducted based on our previous studies [15]. A similar procedure was also used to characterize a flat sheet carbon membrane (without substrate).

\subsection{Membrane Characterization}

Scanning electron microscopy (SEM) was used to observe the membrane structure and morphology. Prior observation, the samples were coated with gold by employing a scanning electron microscope (TM3000, Hitachi) with a potential of $10 \mathrm{kV}$.

\subsection{Pure Gas Permeation Measurements}

Gas permeation system as described in our previous study was used to test the carbon tubular membranes [19,20]. A tubular stainless-steel module of $14 \mathrm{~cm}$ in length was used and the carbon tubular membrane was put inside the module. An O-rings was fitted to the membrane to avoid any leakage on the module. Trans-membrane pressure of 8 bars was applied and pure nitrogen $\left(\mathrm{N}_{2}\right)$ gas $(0.364 \mathrm{~nm})$, carbon dioxide $\left(\mathrm{CO}_{2}\right.$ $(0.330 \mathrm{~nm})$ were fed separately into the module. Equation as described in our previous study [15] was used to calculate the permeance, P/I (GPU) and selectivity, $\alpha$ of the membranes.

\subsection{RESULTS AND DISCUSSION}

\subsection{Scanning Electron Microscopy Analysis}

The SEM images of the surface and cross-section of the polymeric and carbon membrane fabricated at various drying times are shown in Figure 1. As can be seen in the Figure 1(a), the long (needle-shaped), slender rod of NCC particles appeared inside the precursor membrane. This morphology obtained was in agreement with the Kaboorani et. al. (2012), where they also observed a rod-like structure of NCCs with 150$250 \mathrm{~nm}$ [21]. The images also exhibited the rod-like NCCs structures were shorter when literaturely compared with other study conducted by Mohamed et al. (2016), who found the NCC structure was in uniform nanorod or needle-like shapes, however, they still contained both microcrystals and aggregated microcrystals [22]. The size found to be $5.78 \pm 2.14 \mathrm{~nm}$ wide and $121.42 \pm 32.51 \mathrm{~nm}$ long. After underwent carbonization process, the rod or needle-like structures were collapsed. Densification of the transition and macroporous layers occured as the precursor passed their respective Tg's, reflected by a drastic loss in the storage module. The precursor membrane was subjected to 24hours drying times to obtain defect-free polymeric membrane. These results showed that the PI/NCC membrane with dense structure was 
obtained in Figure 1(b) to (e). Unfortunately, Figure 1(b) shows the membrane structure to exhibit a few defects and obviously not dense structure even the sample underwent carbonization process. This is due to the 12 hours drying times is not enough for the membrane to completely dry.



Figure 1 SEM images of the surface and cross-section of the polymeric and carbon membrane fabricated at various drying times.

In addition, it was observed that rough carbon membrane layer surface were obtained for sample (d) and (e), having almost defect structure on carbon membrane surface. Theoretically, increasing the drying times will increasing the defect of the carbon membrane and when the membrane having longer drying times, the membrane tends to syringe and peel-off. This phenomenon will extremely result in reduction of the gas separation performance.

\subsection{Gas Permeation Measurements}

The gas permeation performances of the PI/NCC carbon membrane with different drying times are presented in Table 1. From the gas permeation test, it was revealed that polymeric membrane that went through 24 hours drying times produced better gas permeation performance as compared to others drying times. For all tested membranes, the gas permeance of the selected gases were in the order of $\mathrm{CO}_{2}>\mathrm{N}_{2}$. All selectivity of the gas pair increased dramatically from the polymeric membrane to carbon membrane. The increment of almost 30 time was observed for $\mathrm{CO}_{2} / \mathrm{N}_{2}$ selectivity. The permeation results of all the PI/NCC carbon membranes showed that the gas transport was controlled by the molecular sieving mechanism [12].

Table 1 Gas permeation performance of $\mathrm{PI} / \mathrm{NCC}$ carbon membranes from various drying times

\begin{tabular}{lclc}
\hline \multirow{2}{*}{ Sample } & \multicolumn{3}{c}{ Carbon membrane } \\
\cline { 2 - 4 } & \multicolumn{2}{c}{ Permeance (GPU) } & \multicolumn{1}{c}{ Selectivity } \\
\cline { 2 - 4 } & $\mathbf{N}_{\mathbf{2}}$ & $\mathbf{C O}_{\mathbf{2}} / \mathbf{N}_{\mathbf{2}}$ \\
\hline PI/NCC & $0.94 \pm 3.54$ & $1.92 \pm 3.72$ & $2.40 \pm 2.19$ \\
PI/NCC CM-12 h & $2.87 \pm 2.19$ & $149.21 \pm 4.82$ & $51.99 \pm 3.76$ \\
PI/NCC CM-24 h & $3.22 \pm 3.21$ & $213.56 \pm 2.17$ & $66.32 \pm 2.18$ \\
PI/NCC CM-3days & $2.62 \pm 4.21$ & $106.44 \pm 1.98$ & $40.62 \pm 1.85$ \\
PI/NCC CM-1week & $2.03 \pm 3.21$ & $43.52 \pm 4.22$ & $21.44 \pm 2.53$ \\
\hline
\end{tabular}

\subsection{CONCLUSION}

The influence of drying times on the preparation of the $\mathrm{PI} / \mathrm{NCC}$ carbon membrane was investigated. It was suggested that sufficient drying times must be applied to fabricate carbon membrane with desirable morphological structure. 24 hours drying times provided superior pore structural properties due to the decomposition prior to carbonization process. Longer drying times can lead to defect formation of the carbon membrane which results in extremely low gas separation performance. The 
tubular carbon membrane from 24 hours drying times showed the best drying times with $\mathrm{CO}_{2} / \mathrm{N}_{2}$ selectivity of $66.32 \pm 2.18$.

\section{ACKNOWLEDGEMENT}

The authors would like to acknowledge the financial aids from the Ministry of Higher Education and Universiti Teknologi Malaysia under Higher Institution Centre of Excellence Scheme (Project Number: R. J090301.7846.4J188), Fundamental Research Grant Scheme (Project Number: R. J130000.7846.4F846) and Research University Grant Scheme (Project Number: Q. J130000.2546.03G69). The authors would also like to acknowledge technical and management support from Research Management Centre (RMC), Universiti Teknologi Malaysia. The authors would also gratefully acknowledge the financial support from the Ministry of Higher Education and Universiti Malaysia Pahang under Fundamental Research Grant Scheme (Project Number: Rdu170125).

\section{REFERENCES}

[1] A.-L. Ahmad, Y.-O. Salaudeen, Z.-A. Jawad. 2017. Synthesis of Asymmetric Polyetherimide Membrane for $\mathrm{CO}_{2} / \mathrm{N}_{2}$ Separation. IOP Conf. Ser.: Mater. Sci. Eng. 206: 012068.

[2] T.-A. Centeno, J.-L. Vilas, A.-B. Fuertes. 2004. Effects of Phenolic Resin Pyrolysis Conditions on Carbon Membrane Performance for Gas Separation. J. Membr. Sci. 228: 45-54.

[3] B.-C. Dixit, R.-B. Dixit, D.-J. Desai. 2009. Synthesis, Characterization and Material Application of Novel Polyimide.
Int. J. Polym. Mater. Polym. Biomaterials. 58: 229-242.

[4] A.-B. Fuertes, 2000. AdsorptionSelective Carbon Membrane for Gas Separation. J. Membr. Sci. 177: 9-16.

[5] X. He, M.-B. Hägg. 2012. Structural, Kinetic and Performance Characterization of Hollow Fiber Carbon Membranes. J. Membr. Sci. 390-391: 23-31.

[6] R.-A. Ilyas, S.-M. Sapuan, M.-R. Ishak. 2018. Isolation and Characterization of Nanocrystalline Cellulose From Sugar Palm Fibres (arenga pinnata). Carbohydr. Polym. 181: 1038-1051.

[7] R. Khalilpour, K. Mumford, H. Zhai, A. Abbas, G. Stevens, E.-S. Rubin. 2015. Membrane-based Carbon Capture from Flue Gas: A Review. J. Clean Prod. 103: 286300.

[8] R.-J. Lee, Z.-A. Jawad, A.-L. Ahmad, J.-Q. Ngo, H.-B. Chua. 2017. Improvement of $\mathrm{CO}_{2} / \mathrm{N}_{2}$ Separation Performance by Polymer Matrix Cellulose Acetate Butyrate. IOP Conf. Ser. Mater. Sci. Eng. 206: 012072.

[9] H. Lin, M. Yavari. 2015. Upper Bound of Polymeric Membranes for Mixed-gas $\quad \mathrm{CO}_{2} / \mathrm{CH}_{4}$ Separations. J. Membr. Sci. 475: 101-109.

[10] J. Liu, X. Hou, H.-B. Park, H. Lin. 2016. High-performance Polymers for Membrane $\mathrm{CO}_{2} / \mathrm{N}_{2}$ Separation. Chemistry-A European Journal. 22: 1598015990.

[11] D.-W. Mangindaan, N.-M. Woon, G.-M. Shi, T.-S. Chung. 2015. P84 Polyimide Membranes Modified by a Tripodal Amine for Enhanced Pervaporation Dehydration of Acetone. Chem. Eng. Sci. 122: 14-23. 
[12] S.-A. Ogundare, V. Moodley, W.E. Van Zyl. 2017. Nanocrystalline Cellulose Isolated from Discarded Cigarette Filters. Carbohydr. Polym. 175: 273-281.

[13] K. Rahbar Shamskar, H. Heidari, A. Rashidi. 2016. Preparation and Evaluation of Nanocrystalline Cellulose Aerogels from Raw Cotton and Cotton Stalk. Ind. Crops. Prod. 93: 203-211.

[14] W.-N.-W. Salleh, A.-F. Ismail. 2012. Effects of Carbonization Heating Rate on $\mathrm{CO}_{2}$ Separation of Derived Carbon Membranes. Sep. Purif. Technol. 88: 174-183.

[15] N. Sazali, W.-N.-W. Salleh, A.-F. Ismail, N.-A.-H.-M. Nordin, N.H. Ismail, M.-A. Mohamed, F. Aziz, N. Yusof, J. Jaafar. 2018. Incorporation of Thermally Labile Additives in Carbon Membrane Development for Superior Gas Permeation Performance. J. Nat. Gas Sci. Eng. 49: 376-384.

[16] K.-M. Steel, W.-J. Koros. 2005. An investigation of the Effects of Pyrolysis Parameters on Gas Separation Properties of Carbon Materials. Carbon. 43: 18431856.

[17] C. Wang, L. Ling, Y. Huang, Y. Yao, Q. Song. 2015. Decoration of Porous Ceramic Substrate with Pencil for Enhanced Gas Separation Performance of Carbon Membrane. Carbon. 84: 151-159.

[18] M.-Y. Zhang, H.-Q. Niu, S.-L. Qi, G.-F. Tian, X.-D. Wang, D.-Z. Wu. 2014. Structure Evolutions
Involved in the Carbonization of Polyimide Fibers with Different Chemical Constitution. Mater. Today Commun. 1: 1-8.

[19] N. Sazali, W.-N.-W. Salleh, A.-F. Ismail, N.-H. Ismail, N.Yusof, F.Aziz， J. Jaafar.N.-A.-H.-M. Nordin. 2018. Controlled Dipcoating Times for Improving $\mathrm{CO}_{2}$ Selective of PI/NCC based Supported Carbon Membrane. $J$. Membr. Sci. Tech. 8:1.

[20] N. Sazali, W.-N.-W. Salleh, A.-F. Ismail, N.-H. Ismail, F. Aziz, N. Yusof, H. Hasbullah. 2018. Effect of Stabilization Temperature During Pyrolysis Process of P84 co-polyimide-based Tubular Carbon Membrane for $\mathrm{H}_{2} / \mathrm{N}_{2}$ and $\mathrm{He} / \mathrm{N}_{2}$ Separations. IOP Conf. Ser.: Mater. Sci. Eng. 342: 012027

[21] A. Kaboorani, B. Riedl, P. Blanchet, M. Fellin, O. Hosseinaei, S. Wang. 2012. Nanocrystalline Cellulose (NCC): A Renewable NanoMaterial for Polyvinyl Acetate (PVA) Adhesive. European Poly. J. 48: 1829-1837.

[22] M.-A. Mohamed, W.-N.-W. Salleh, J Jaafar, A.-F Ismail, M.A Mutalib, N.-A.-A. Sani, S.-E.A.Asri, C.-S Ong. 2016. Physicochemical Characteristic of Regenerated Cellulose/Ndoped $\mathrm{TiO}_{2} \quad$ Nanocomposite Membrane Fabricated from Recycled Newspaper with Photocatalytic Activity under UV and Visible Light Irradiation. Chem. Eng. J. 284: 202-215. 